\title{
EXPRESSÃO DA GLICOPROTEÍNA-P E MRP1 EM TECIDOS DE CÃES COM LEISHMANIOSE VISCERAL
}

\author{
P-GLYCOPROTEIN AND MRP1 EXPRESSION IN TISSUES FROM DOGS WITH VISCERAL \\ LEISHMANIASIS
}

\author{
A. M. C. CALADO ${ }^{*}$, R. A. N. RAMOS ${ }^{2}$, R. J. CINTRA ${ }^{3}$, L. C. ALVES ${ }^{4}$, \\ M. TINUCCI-COSTA ${ }^{1}$
}

\section{RESUMO}

Glicoproteína-P (gp-P) e proteína de resistência a múltiplas drogas (MRP1) são bombas de efluxo responsáveis pelo fenótipo MDR (resistência a múltiplas drogas). Neste trabalho, investigamos a expressão por imuno-histoquímica da gp-P e MRP1 em amostras de tecidos de 24 cães com Leishmania infantum (syn. L. chagasi), e avaliamos se a leishmaniose visceral canina (LVC) induz a MDR em cães, tendo a expectativa de que os resultados obtidos possam oferecer perspectivas de uma abordagem terapêutica mais segura e eficaz nesta doença. Os resultados mostraram que a expressão da gp-P nas amostras de cães com LVC foi maior $(\mathrm{p}<0,05)$ em todos os tecidos em comparação ao grupo controle, com exceção da pele, que não diferiu. Entretanto, apenas as glândulas adrenais nas amostras LVC, em comparação as controle, expressaram significativamente mais MRP1 ( $\mathrm{p}<0,05)$. As expressões de gp-P e MRP1 foram menores $(\mathrm{p}<0,05)$ no baço e pele das amostras LVC positivas, em comparação aos demais tecidos. Os resultados sugerem que a falha da cura parasitológica poderia ser devido à alta expressão da gp-P e MRP1 no fígado, adrenal e rins, por impedir a ação parasiticida dos fármacos recomendados no tratamento.

PALAVRAS-CHAVE: Cão. Glicoproteína-P. Imuno-histoquímica. Leishmania infantum. MDR. MRP1.

\section{SUMMARY}

P-Glycoprotein (P-gp) and multidrug resistance-associated protein 1 (MRP1) are efflux pumps responsible for the MDR phenotype (multidrug resistance). In this work, we will investigate the immunohistochemical expression of P-gp and MRP1 in 24 tissue samples from dogs with Leishmania infantum (syn. L. chagasi) and evaluate whether canine visceral leishmaniasis (CVL) induces MDR in dogs. The expectation is that the results obtained from this research may offer prospects for a safer and more effective therapeutic approach for this disease. Findings illustrated that the expression of P-gp in CVL affected tissue samples $(\mathrm{p}<0.05)$ was greater than those of the control group, with the exception of skin tissue samples which did not differ. However, only the adrenal gland samples affected by LVC expressed significantly more MRP1 $(p<0.05)$ than the control group. The expressions of P-gp and MRP1 were lower $(p<0.05)$ in LVC positive spleen and skin samples in comparison with other tissues. These results suggest that the lack of a parasitological cure could be due to the high expression of P-gp and MRP1 in the liver, adrenal glands, and kidneys, which block the action of parasitacidal drugs recommended in treatment.

KEY-WORDS: Dog. Immunohistochemical. Leishmania infantum. P-glycoprotein. MDR. MRP1.

\footnotetext{
${ }^{1}$ Universidade Estadual Paulista - Jaboticabal - Departamento de Clínica e Cirurgia Veterinária. Email.: andreacaladovet@hotmail.com

${ }^{2}$ Università degli Studi di Bari - Itália.

${ }^{3}$ Universidade Federal de Pernambuco - Departamento de Estatística.

${ }^{4}$ Universidade Federal Rural de Pernambuco - Departamento de Medicina Veterinária.
} 


\section{INTRODUÇÃO}

A Leishmaniose Visceral Canina (LVC) é uma doença sistêmica e crônica, distribuída mundialmente, causada por protozoário do gênero Leishmania. No Brasil, o agente etiológico é da espécie Leishmania infantum (syn. L. chagasi), transmitida principalmente por um flebotomíneo da espécie Lutzomyia longipalpis (DANTAS-TORRES\& BRANDÃO-FILHO, 2006; KUHLS et al., 2011). As opções existentes de tratamento para LVC não são satisfatoriamente efetivas e seguras, pois não eliminam completamente o parasita (PARADIES et al., 2012). Porém, diversos pesquisadores a indicam, pois induz a melhora clínica e pode atrasar a progressão da doença, além da redução da carga parasitária (RIBEIRO et al., 2013); No entanto, o arsenal de fármacos é limitado, constituindo um impedimento importante para o controle da enfermidade, e o aparecimento de resistência aos medicamentos pode comprometer a utilização dos mesmos (ROUGIER et al., 2012).

Um dos mecanismos que poderia explicar a falta de eficácia dos fármacos e o desenvolvimento de resistência é a ativação das proteínas da família transportadoras ABC (ATP Binding Cassete). Esses transportadores promovem o efluxo de diferentes substâncias da célula, abrangendo uma gama de medicamentos com diferentes estruturas e objetivos, surgindo então, o fenótipo MDR (resistência a múltiplas drogas) (SCHRICKX \& FINKGREMMELS, 2008).

A gp-P, primeira proteína do tipo $\mathrm{ABC}$ a ser descoberta, atua como uma bomba capaz de expulsar xenobióticos do citoplasma de diferentes tipos celulares, limitando o efeito citotóxico das mesmas no seu local de ação (JULIANO \& LING, 1976; STAVROVSKAYA, 2000). Está expressa em células tumorais e em tecidos normais de cães, tais como fígado, epitélio tubular renal, córtex da adrenal, epitélio do cólon e barreira hematoencefálica (GIN, 1996). Fisiologicamente a gp-P tem como função impedir a absorção de compostos tóxicos (HENNESSY \& SPIERS, 2007), podendo interferir na absorção, distribuição, metabolização e excreção de fármacos, com redução da biodisponibilidade dos mesmos (ROULET et al., 2003). Outro mecanismo de MDR esta ligado a MRP (proteína associada à resistência a múltiplas drogas). Sabe-se que existe um total de 9 membros (MRP1-9), porém a mais estudada é a MRP1 (BERGMAN, 2003; GOTTESMAN et al., 2002). Ela age aumentando o efluxo das xenobióticos, resultando na redução do acúmulo intracelular das mesmas (LOE et al., 1996). O papel fisiológico da MRP1 envolve o transporte de compostos excretórios e eliminação de xenobióticos, além de mediação da resposta inflamatória. São amplamente expressas, principalmente em tecidos importantes para absorção, metabolismo e eliminação (LESLIE et al., 2005).

Este estudo teve como propósito investigar se a LVC poderia induzir resistência a múltiplas drogas, por meio do estímulo ou aumento da expressão da gp-P e MRP1, em cães com infecção naturalmente adquirida, com a expectativa de que os resultados obtidos possam oferecer perspectivas de uma abordagem terapêutica mais segura e eficaz nesta doença, além de fornecer mais subsídios às autoridades de saúde pública.

\section{MATERIAL E MÉTODOS}

O protocolo experimental deste estudo foi aprovado pela Comissão de Ética no Uso de Animais (CEUA - Unesp/Jaboticabal), sob número 007763/10.

Amostras de pele, rins, glândulas adrenais, fígado e baço foram obtidas de 24 cães com sorologia (Imunofluorescência indireta e ELISA) e imunohistoquímica positivas para Leishmania infantum, oriundos do Centro de Controle de Zoonoses (CCZ) das cidades de Caruaru e Petrolina, no Estado de Pernambuco, Brasil. Amostras de tecidos dos mesmos órgãos foram colhidas de três cães sadios, de área não endêmica, imediatamente depois de declarado o óbito por causas naturais, durante atendimento emergencial no Hospital Veterinário da UNESP, campus de Jaboticabal, SP, que serviram como grupo controle.

Os cães soropositivos para LV, de sexos e idades variados, após passarem por exame físico, receberam uma aplicação de $4 \mathrm{mg} / \mathrm{kg}$ de Cloridrato de Lidocaína (Cloridrato de Lidocaína 2\%, Hipolabor, Brasil), como anestésico local, para coleta de amostras da pele na face interna do pavilhão auricular, com auxilio de "punch" com diâmetro de $4 \mathrm{~mm}$. Após a coleta, receberam injeção letal de Thionembutal a 30\% (Tiopental sódico - Abbot Laboratórios do Brasil) em dose suficiente para produzir parada cardíaca, conforme protocolos estabelecidos nos CCZs de Pernambuco, Brasil. Após a confirmação dos óbitos, realizaram-se as necropsias, durante as quais foram coletadas as amostras em frascos com solução de formol a $10 \%$ tamponado com fosfatos, na qual permaneceram por um período aproximado de 48 horas, sendo então transferidas para álcool $70^{\circ}$.

Os anticorpos anti-gp-P (clone C494 SignetLaboratories, Inc. Dedham, MA, USA, Cód. 872001) e anti-MRP1 (clone MRP1- Novocastra Laboratories Ltd, Newcastle, UK, Cód. NCL-MRP1) utilizados na imuno-histoquímica foram produzidos em camundongos contra antígenos humanos e seguiu-se a metodologia descrita por Gerardi et al. (2014) com algumas modificações. A expressão da MRP1 e gp-P foram pesquisados em cortes de $3 \mu \mathrm{m}$ de espessura montados em lâminas pré-tratadas com Poly-L-lisina (Cód. P4832 Sigma ChemicalCo., St Louis, MO EUA). As lâminas contendo os cortes foram colocadas em estufa a $60^{\circ} \mathrm{C}$ por 30 minutos, seguiu-se os processos de desparafinização, hidratação e bloqueio da peroxidase endógena (peróxido de hidrogênio a $8 \%$ em metanol, por 30 minutos). A recuperação antigênica para o anticorpo anti-MRP1 foi feita com tampão tris-EDTA (pH 9,0), em panela de pressão, cozendo por 5 minutos, e em tampão citrato $(\mathrm{pH}$ $6,0)$ pré-aquecido a $92^{\circ} \mathrm{C}$ em banho-maria para gp-P por 30 minutos. Seguiu-se o bloqueio das reações inespecíficas (Leite em pó Molico ${ }^{\mathrm{R}}$ - Nestlé Brasil LTDA) por 30 minutos e a incubação $\left(4^{\circ} \mathrm{C}\right)$ com os anticorpos primários MRP1 ou gp-P, nas diluições de 1:25 e 1:200, respectivamente, durante 18 horas. Subsequentemente, as 
lâminas foram incubadas com o anticorpo secundário (Envision ${ }^{\circledR}$ - DAKO North América, Carpinteria) durante 60 minutos para a gp-P e com o sistema de detecção de polímeros (MACH 4 - Biocare Medical, Concord) durante 30 minutos para a MRP1. Finalmente, as reações foram reveladas pelo substrato cromogênico, 3,3 diaminobenzendina (Cód. SK4100 - DAB - Vector Laboratories, Burlingame, CA, EUA), contra coradas com a hematoxilina de Harris por um minuto, desidratadas e montadas.

Como controle positivo e negativo das reações utilizou-se cólon canino (amostra que sabidamente expressam essas proteínas); no caso do controle negativo, também substituiu-se o anticorpo primário por imunoglobulina G de camundongo (Dako North America, Carpinteria), mesma espécie em que foi produzido o anticorpo primário.

A frequência das imunomarcações foi obtida através das contagens de 100 células do tecido, entre marcadas e não marcadas, com auxílio de um retículo micrométrico (Nikon, Inc. - Japan) em aumento de $400 x$, em cinco campos por corte. Destes foram extraídas porcentagens de células marcadas em relação ao total (GERARDI et al., 2014).

Exceto os dados relacionados ao rim do grupo controle da MRP1, todas as variáveis atenderam as pressuposições de normalidade de acordo com o teste de Jarque-Bera.

Dados identificados com distribuição normal foram submetidos ao teste $\mathrm{t}$ para médias de duas amostras independentes. Caso contrário, os dados foram submetidos ao teste de Wilcoxon. Em todas as situações, o nível de significância considerado foi $\mathrm{p}<0,05$.

\section{RESULTADOS E DISCUSSAO}

As amostras de fígado, baço, rins e adrenais dos 24 cães LV positivos mostraram imunorreatividade aos anticorpos monoclonais anti-glicoproteína-P, clone C494, e anti-MRP1, clone MRP1. Todas as 24 amostras de pele foram reativas ao clone MRP1, e 21 delas ao C494, apesar de ser a maioria das amostras, o número de células reativas na pele ao clone C494 foi menor do que em relação aos outros tecidos. Também exibiram reatividade as amostras de cólon canino, sem alterações patológicas, que foram utilizados como controle positivo das reações, e todas as amostras dos animais do grupo controle. Embora estes clones tenham sido concebidos para uso em humanos e animais de laboratório, tecidos caninos também são reativos, como visto neste estudo e nos de Ginn (1996) e de Gerardi et al. (2014).

A localização da imunomarcação da gp-P foi em membrana plasmática nas amostras de fígado, com total delineamento do hepatócito (Figura 1), e no córtex das adrenais; citoplasmática e granular na polpa branca e vermelha do baço, na epiderme e glândulas sudoríparas e sebáceas e no epitélio tubular renal. A intensidade de coloração variou de moderada a intensa. Esses achados foram parcialmente congruentes ao descrito por Ginn (1996), que descreveu padrão de marcação semelhante em vários órgãos (fígado, glândula adrenal, cólon, rim, estômago, pâncreas, ductos das glândulas salivares), marcação não uniforme na epiderme, entretanto não obteve marcação em baço, discordando dos nossos resultados. Diferenças nos procedimentos laboratoriais adotadas poderiam justificar a ausência de marcação no baço. Uma das possibilidades poderia estar relacionada a diferenças no sistema de recuperação antigênica. Enquanto Ginn (1996) utilizou um sistema enzimático, em nossa pesquisa utilizamos o calor. Além deste, o tipo e o tempo de fixação e armazenamento das amostras também poderiam interferir nos resultados, mas esses dados não foram detalhados na publicação.

Já na MRP1, todos os tecidos apresentaram marcação citoplasmática, de aspecto granular, com intensidade de coloração que variou de intensa a moderada (Figura 2), semelhante ao que ocorre em tecidos humanos, onde é onipresente (BORST et al., 2000). Nos caninos sua expressão já foi assinalada em fígado, rim, intestino, pulmão, cérebro e testículo (CONRAD et al., 2001).

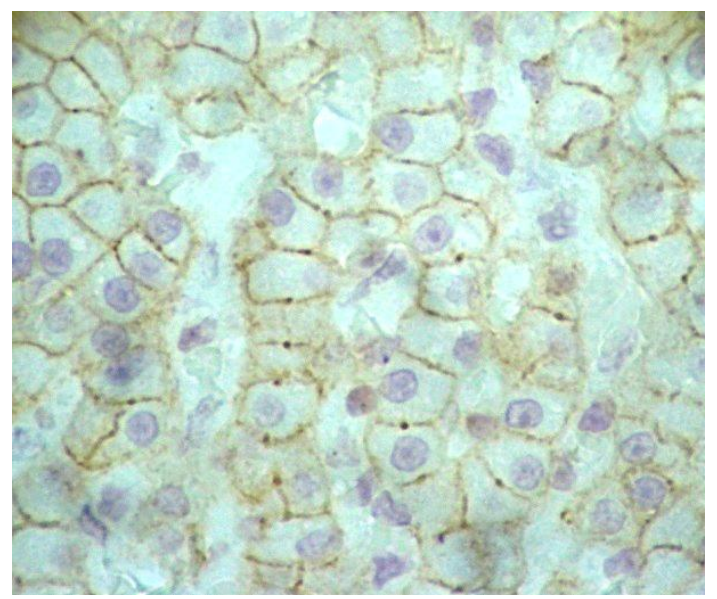

Figura 1 - Fotomicrografia de fígado de cão com LVC imunomarcado pelo anticorpo anti-glicoproteína-P (clone c494), mostrando marcação de membrana com total delineamento dos hepatócitos. Contracoloração com hematoxilina de Harris. Obj. 40x. 


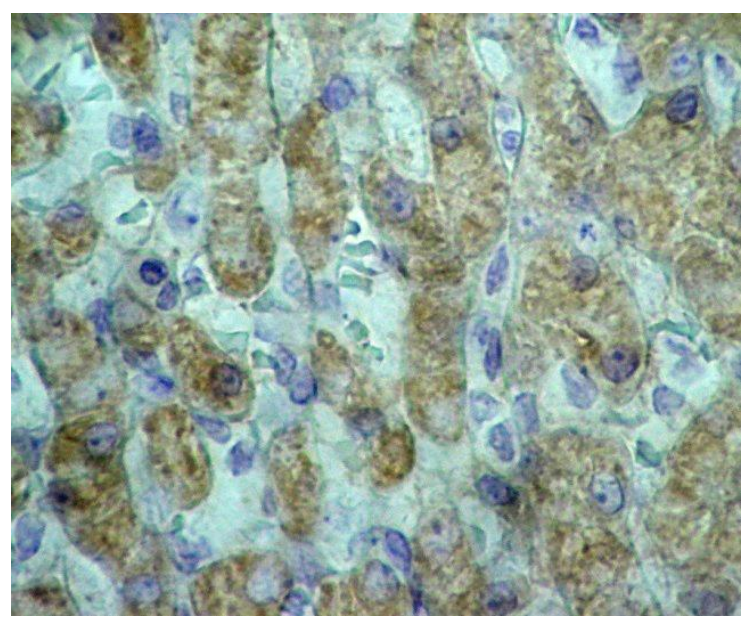

Figura 2 - Fotomicrografia de fígado de cão com LVC imunomarcado pelo anticorpo anti-MRP1 (clone MRP1), mostrando marcação citoplasmática granular nos hepatócitos. Contracoloração com hematoxilina de Harris. Obj. 40x.

Estatisticamente, com relação à porcentagem de células marcadas com o anticorpo para a gp-P (Tabela 1), a expressão foi significativamente maior $(p<0,05) \mathrm{em}$ todos os tecidos LVC positivos em relação ao grupo controle, com exceção da pele, que não diferiu. Variação na expressão da gp-P em tecidos humanos também foi identificada por Gottesman \& Pastan (1993). Esses pesquisadores observaram que a expressão da gp-P pode variar de muito baixo a indetectável nas células epidérmicas, a níveis altos no córtex da adrenal e epitélio tubular renal.
Entretanto, avaliando a média de células imunomarcadas para o anticorpo MRP1 (Tabela 1), apenas as amostras das glândulas adrenais LVC positivas em comparação as amostras controle expressaram significativamente mais MRP1 $(\mathrm{p}<0,05)$. E analisando em conjunto os resultados das imunomarcações exclusivamente entre as amostras LVC positivas pode-se observar que a gp-P e a MRP1 apresentaram expressões significativamente menores $(\mathrm{p}<0,05)$ no baço e pele, em comparação aos demais tecidos testados, os quais não diferiram entre si.

Tabela 1 - Valores médios das porcentagens (média \pm desvio padrão) de imunomarcação pela técnica de imunohistoquímica para a glicoproteína-P (gp-P) e MRP1 em amostras de adrenal, fígado, rins, baço e pele de cães com leishmaniose visceral canina (LVC) e grupo controle.

\begin{tabular}{ccccc}
\hline & $\begin{array}{c}\text { gp-P } \\
(\mathbf{L V C})\end{array}$ & gp-P (controle) & MRP1 (LVC) & MRP1 (controle) \\
\hline Adrenal & $79,2 \pm 12,9$ & $0,7 \pm 0,6$ & $79,2 \pm 9,9$ & $53,1 \pm 12,2$ \\
Fígado & $75,9 \pm 8,7$ & $3,5 \pm 3,1$ & $74,6 \pm 10,4$ & $60,7 \pm 2,7$ \\
Rins & $72,1 \pm 21,0$ & $21,1 \pm 22,2$ & $70,1 \pm 21,9$ & $77,7 \pm 12,7$ \\
Baço & $35,0 \pm 15,1$ & $9,8 \pm 7,8$ & $37,5 \pm 11,7$ & $26,0 \pm 0,2$ \\
Pele & $12,1 \pm 10,4$ & $22,3 \pm 26,1$ & $28,7 \pm 14,2$ & $14,9 \pm 11,3$ \\
\hline
\end{tabular}

Embora até o momento não existam trabalhos que correlacionem a expressão dessas proteínas em tecidos caninos, muito menos em cães com LV, esses resultados podem sugerir, ao menos em parte, a redução da parasitemia cutânea de cães durante o tratamento com antimoniato associado ao alopurinol, bloqueando a transmissão de parasitos encontrados na pele para os flebotomíneos (DANTAS-TORRES et al., 2012).

Para alguns pesquisadores, há correlação positiva entre a carga parasitária em baço e pele com o estado clínico da doença, sendo este parâmetro importante no acompanhamento da terapia (FERRER et al., 1988; REIS et al., 2006). Esses mesmos órgãos foram considerados os principais sítios de localização e proliferação da LVC, e em menor intensidade o fígado (ALVES et al., 2009). Outros pesquisadores comentam que nos rins e glândulas adrenais, o parasita também não é facilmente encontrado (FERRER et al., 1988; TAFURI et al., 2004). Todavia, para Reis et al. (2006) o baço e a pele do pavilhão auricular são mais intensamente parasitados, independente da sintomatologia clínica.

Como a pele apresenta baixa expressão desses marcadores de resistência a múltiplas drogas, é possível que os fármacos antiprotozoários administrados corretamente exerçam atividade parasiticida eficiente na pele. Talvez por isso, o cão durante o tratamento apresente-se negativo nos testes que pesquisam a parasitemia cutânea, tendo em vista que alguns fármacos 
podem proporcionar em torno de $93 \%$ de cura clínica, como no caso da anfotericina B. Todavia, a interrupção ou falha na administração dos fármacos proporciona a reincidência da parasitemia cutânea (RIBEIRO \& MICHALICK, 2001). Isto sugere que durante o tratamento, o parasita possa ficar albergado em outros órgãos, possivelmente nos que expressem elevados níveis desses marcadores de resistência a múltiplas drogas, nos quais os fármacos não conseguem atingir concentrações suficientes para exercerem sua atividade.

Mesmo com a cura clínica, até o momento não existe a cura parasitológica no cão (PARADIES et al., 2012) e apesar da baixa densidade parasitária no fígado, adrenal e rins, foi verificado neste trabalho que estes órgãos apresentaram maior expressão da gp-P em comparação com o grupo controle, enquanto a MRP1 apenas nas glândulas adrenais. Isto sugere que nestes órgãos os fármacos leishmanicidas não consigam exercer sua atividade, favorecendo a permanência do parasita no interior da célula e, consequentemente, a não erradicação da doença no cão.

Estudos posteriores poderiam ser realizados, como a análise desses marcadores em tecidos de cães sob tratamento para LVC, muito embora possam existir outros fatores que podem influenciar na resistência a fármacos, tais como o aparecimento de cepas resistentes; a presença de homólogos desses marcadores na Leishmania infantum e a própria resposta imunológica do cão. Outra linha de pesquisa interessante seria a utilização de fármacos inibidores dessas proteínas, como o verapamil, e avaliar se os cães apresentam melhores na resposta ao tratamento.

Os resultados deste estudo, nas condições em que foi desenvolvido, permitiram mostrar que a presença dessas bombas de efluxo em células do fígado, das glândulas adrenais e dos rins, principalmente, podem favorecer o parasita na sua sobrevivência contra os fármacos anti-leishmania.

\section{REFERÊNCIAS}

ALVES, C. F.; AMORIM, I. F. G.; MOURA, E. P.; RIBEIRO, R.; ALVES, C. F.; MICHALICK, M. S.; KALAPOTHAKIS, E.; BRUNA-ROMERO, O.; TAFURI, W. L.; TEIXEIRA, M. M.; MELO, M. N. Expression of IFN-y, TNF-alfha, IL-10 and TGF-Betha in limph nodes associates with parasite load and clinical form of disease in dogs naturally infected with Leishmania (Leishmania) chagasi. Veterinary Immunology and Immunopathology, v.128, n.4, p.349358, 2009.

BERGMAN, P. J. Mechanisms of anticancer drug resistance. The Veterinary Clinics of the North America - Small Animal Practice, v.33, n.3, p.651-667, 2003.

BORST, P.; EVERS, R.; KOOL, M.; WIJINHOLDS, J. A family of drug transports: the multidrug resistance-associated proteins. Journal of the National Cancer Institute, v.92, n.16, p.1295-1302, 2000.

CONRAD, S.; VIERTELHAUS, A.; ORZECHOWSKI, A.; HOOGSTRAATE, J.; GJELLAN, K.; SCRENK, D.;
KAUFFMANN, H. M. Sequencing and tissue distribution of canine MRP2 gene compared with MRP1 and MDR1. Toxicology, v.156, n.2-3, p.81-91, 2001.

DANTAS-TORRES, F.; BRANDAO-FILHO, P. S. Visceral leishmaniasis in Brazil: revisiting paradigmas of epidemiology and control. Revista do Instituto de Medicina Tropical de São Paulo, v.48, n.3, p.151-156, 2006.

DANTAS-TORRES， F.; SOLANO-GALEGO, L.; JANETH, G.; RIBEIRO, V. M.; CAVALCANTI, M. P.; OTRANTO, D. Canine leishmaniosis in the Old and New Worlds: unveiled similarities and differences. Trends in Parasitology, v.28, n.12, p.531-538, 2012.

FERRER, L.; RABANAL, R. M.; DOMINGO, M.; RAMOS, J. A.; FONDEVILA, D. Identification of Leishmania donovani amastigotes in canine tissues by immunoperoxidase staining. Research in Veterinary Science, v.44, n.2, p.194-196, 1988.

GERARDI, D. G.; TINUCCI-COSTA, M.; SILVEIRA, A. C. T.; MORO, J. V. Expression of P-glycoprotein, multidrug resistance-associated protein, glutathione-Stransferase pi and p53 in canine transmissible veneral tumor. Revista Pesquisa Veterinária Brasileira, v.34, n.1, p.71-78, 2014.

GINN, P. E. Immunohistochemical detection of Pglycoprotein in formalin-fixed and paraffin-embedded normal and neoplastic canine tissues. Veterinary Pathology, v.33, n.5, p.533-543, 1996.

GOTTESMAN, M. M.; FOJO, T.; BATES, S. E. Mulidrug resistance in cancer: role of ATP-dependent transporters. Nature Reviews Cancer, v.2, n.1, p.48-58, 2002.

GOTTESMAN, M. M.; PASTAN, I. Biochemistry of multidrug resistance mediated by the multidrug transporter. Annual Review of Biochemistry, v.62, p.385-427, 1993.

HENNESSY, M.; SPIERS, J. P. A primer on the mechanics of P-glycoprotein the multidrug transporter. Pharmacological Research, v.55, n.1, p.1-15, 2007.

JARQUE, C. M.; BERA, A. K. A test for normality of observations and regression residuals. International Statistical Review, v.55, n.5, p.163-172, 1987.

JULIANO, R. L.; LING, V. A. A surface glycoprotein modulating drug permeability in Chinese hamster ovary cell mutants. Biochimica et Biophysica Acta, v. 455, n.1, p.152-162, 1976.

KUHLS, K.; ALAM, M. Z.; CUPOLILLO, E.; FERREIRA, G. E. M.; MAURICIO, I. L.; ODDONE, R.; FELICIANGELI, M. D.; WIRTH, T.; MILES, M. A.; SCHONIAN, G. Comparative Microsatellite Typing of New World Leishmania infantum Reveals Low Heterogeneity among Populations and Its Recent Old 
World Origin. PLoS Neglected Tropical Diseases, v.5, n.6, p.1-16, 2011.

LESLIE, E. M.; DEELEY, R. G.; COLE, S. P. C. Multidrug resistance proteins: role of P-glycoprotein, MRP1, MRP2 and BCRP (ABCG2) in tissue defense. Toxicology and Applied Pharmacology, v.204, n.3, p.216-237, 2005.

LOE, D. W.; ALMQUIST, K. C.; DEELEY, R. G.; COLE, S. P. Multidrug resistance protein (MRP)mediated transport of leukotriene C4 and chemotherapeutic agents in membrane vesicles. Demonstration of glutathione-dependent vincristine transport. Journal of Biological Chemistry, v.271, n.15, p.9675-9682, 1996.

PARADIES, P.; SASANELLI, M.; AMATO, M. E.; GRECO, B.; DE PALO, P.; LUBAS, G. Monitoring the reverse to normal of clinico-pathological findings and the disease free interval time using four different treatment protocols for canine leishmaniosis in an endemic area. Research in Veterinary Science, v.93, n.2, p.843-847, 2012.

REIS, A. B.; MARTINS-FILHO, O. A.; TEIXEIRACARVALHO, A.; CARVALHO, M. G.; MAYRINK, W.; FRANÇA-SILVA, J. C.; GIUNCHETTI, R. C.; GENARO, O.; CORREA-OLIVEIRA, R. Parasite density and impaired biochemical/hematological status are associated with severe clinical aspects of canine visceral leishmaniasis. Research in Veterinary Science, v.81, n.1, p.68-75, 2006.

RIBEIRO, V. M.; MICHALICK, M. S. M. Protocolos terapêuticos e controle da leishmaniose visceral canina. Revista Nosso Clínico, v.4, p.10-20, 2001.
RIBEIRO, V. M.; SILVA, S. M.; MENZ, I.; TABANEZ, P.; NOGUEIRA, F. S.; WERKHAÜSER, M.; FONSECA, A. L. S.; DANTAS-TORRES, F. Control of visceral leishmaniasis in Brazil: recommendations from Brasileish. Parasites \& Vectors, v.6, n.8, p.1-2, 2013.

ROUGIER, S.; HASSEINE, L.; DELAUNAY, P.; MICHEL, G.; MARTY, P. One-year clinical and parasitological follow-up of dogs treated with marbofloxacin for canine leishmaniasis. Veterinary Parasitology, v.186, n.3-4, p.245-253, 2012.

ROULET, A.; PUEL, O.; GESTA, S.; LEPAGE, J. F.; DRAG, M.; SOLL, M.; AVINERIE, M.; PINEAU, T. MDR1-deficient genotype in Collie dogs hypersensitive to the P-glycoprotein substrate ivermectin. European Journal of Pharmacology, v.460, n.2-3, p.85-91, 2003.

SCHRICKX, J. A.; FINK-GREMMELS, J. Implications of $\mathrm{ABC}$ transporters on the disposition of typical veterinary medicinal products. European Journal of Pharmacology, v.585, n.2-3, p.510-519, 2008.

STAVROVSKAYA, A. A. Cellular mechanisms of multidrug resistance of tumor cells. Biochemistry, v.65, n.1, p.95-106, 2000.

TAFURI, W. L.; SANTOS, R. L.; ARANTES, R. M. E.; GONÇALVES, R.; MELO, M. N.; MICHALICK, M. S. M.; TAFURI, W. L. An alternative immunohistochemical method for detecting Leishmania amastigotes in paraffin-embedded canine tissues. Journal of Immunological Methods, v.292, n.1-2, p.17-23, 2004.

WILCOXON, F. Some rapid approximate statistical procedures. Annals of the New York Academy of Sciences, v.52, p.808-814, 1950. 